\title{
INFÂNCIA E MELANCOLIA, UMA ABORDAGEM EM TRÊS ESTAÇÕES
}

Academicismo e Modernismo na América Latina. ${ }^{[1]}$

\author{
Rosângela Cherem ${ }^{[2]}$ e Letícia Weiduschadt ${ }^{[3]}$ \\ Participantes do Grupo de Pesquisa: Ana Lúcia Gil, Kamilla Nunes, \\ Letícia Weiduschadt e Rachel Reis de Araújo ${ }^{[4]}$
}

RESUMO: Através de rostos infantis que remetem a sentimentos de melancolia, vazio e solidão, os pintores Isaías Cabezón Acevedo, Fídolo Alfonso González, Ramon Cornet Gomez e Raul Soldi problematizam a infância menos pela abordagem biográfica ou pelo retrato e mais como uma experiência recôndita e distante que se assemelha a uma doença da alma, da qual cada um se aproxima de modo muito singular, tangenciando uma espécie de cena muito intima que guarda as sensibilidades e percepções do artista em sua relação com a sua própria criação.

PAlAVRAS-CHAVE: Academicismo; Modernismo; Teoria e Crítica de Arte; Arte LatinoAmericana; História da Arte.

Na mitologia grega, Perséfone, filha de Zeus e Demeter, era uma bela jovem que vivia num lugar tranqüilo e agradável. Certo dia estava a colher flores num bosque quando, vindo à cavalo, Hades irrompeu do chão e enlaçou seu braço subitamente ao redor da cintura da jovem puxado-a para o interior de sua carruagem. Estava decidido a levar Perséfone para torná-la a nova rainha do sombrio mundo dos mortos. Assim, com o desaparecimento da filha, a mãe deu início a uma busca incansável e desesperada, embora ninguém soubesse seu paradeiro e os que soubessem não quisessem enfrentar a ira do poderoso raptor. Zeus sabia onde estava sua filha, entretanto, não queria enfrentar seu irmão, pois caso obrigasse o deus do mundo dos mortos a devolver sua filha à mãe, poderia desencadear uma fúria

\footnotetext{
${ }^{[1]}$ Projeto Academicismo e Modernismo na América Latina.

${ }^{[2]}$ Rosângela Miranda Cherem. Professora do Departamento de Artes Plásticas do Centro de Artes, UDESC.

${ }^{[3]}$ Acadêmica do Curso de Licenciatura em Artes Plásticas. Ceart / UDESC. Bolsista PROBIC / UDESC.

${ }^{[4]}$ Acadêmicas participantes do Projeto Academicismo e Modernismo na América Latina, do mesmo grupo de pesquisa das orientadoras Rosângela Miranda Cherem (coordenadora do projeto) e Sandra Makowiecky (docente participante), além de Kamilla Nunes bolsista PROBIC, acadêmica do curso de Licenciatura em Artes Plásticas; Letícia Weiduschadt, bolsista PROBIC, acadêmica do curso de Licenciatura em Artes Plásticas; Ana Lúcia Gil, bolsista PROBIC, acadêmica do curso de Licenciatura em Artes Plásticas e Raquel Reis, bolsista voluntária, acadêmica do curso de Licenciatura em Artes Plásticas.
} 
incontrolável. Com o passar dos dias e meses os cereais começaram a faltar, o povo começou a ter fome e o mundo em que viviam passou rapidamente a um inverno amargo e rigoroso.

Com esta decadência no mundo em que viviam, Zeus decide que Perséfone deveria regressar ou toda a população estava condenada. Ocorre que ela só poderia regressar caso não tivesse comido nada no mundo dos mortos, mas isto era impossível já que passara meses neste mundo obscuro, tendo comido quatro grãos de romãs. $\mathrm{O}$ deus do Olimpo ficou numa posição difícil, pois se a filha não voltasse o mundo pereceria. Decidiu-se então que ela retornaria aos braços da mãe, mas teria que regressar todos os anos pela mesma quantidade de meses tal qual o número de grãos de romãs que comera. Assim, o mundo tinha suas variações climáticas de acordo com a presença de Perséfone junto à mãe (quente e úmido), junto ao ambiente terreno (morno, insosso e seco) ou junto ao reino de Hades (gélido e chuvoso).

Considerando estas variações atmosféricas como complexidades emocionais familiares ao artista e cujas sensações foram trabalhadas através dos temas, cores, linhas e formas, o presente artigo aborda algumas pinturas latino-americanas onde os retratos infantis comparecem não apenas como tema, mas também como sensibilidades e percepções relacionadas ao extravio e à solidão, à distância e ao isolamento na relação do artista com o mundo. Assim sobrepõem-se duas situações: a de Perséfone, cujo destino não lhe pertence, sendo seu tempo decidido alhures e a da criança, cujas escolhas e desejos constantemente lhe escapam pelo turbilhão das decisões do mundo adulto.

\section{Quando o mundo se faz quente e úmido.}

Consideremos as cores quentes e o contraste com os olhos e lábios chorosos de uma criança como ecos que se reproduzem e vibram no vácuo. Observemos o olhar distante e esvaziado de Perséfone junto à mãe satisfeita da qual a filha logo se afastará novamente para seguir no destino cíclico e sem fim contra o qual nada pode fazer, direcionado a um nada, para um lugar que apenas ressoa e não alcançamos. No rosto sombrio que guarda um inalcançável desconsolo, nesse esquecimento de si mesmo, no contraste com os tons rosáceos do plano de fundo com o vermelho da blusa de um

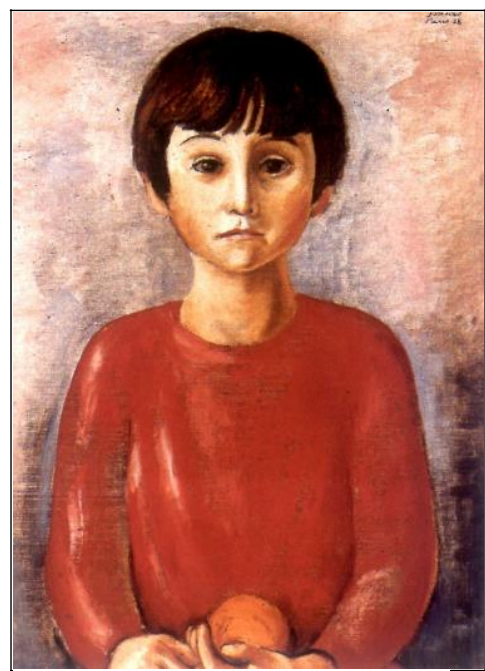

Figura 1 menino, Isaías Cabezón Acevedo (1891 - 1963), artista chileno retrata "Niño de la naranja". Muitas das obras do pintor se destacam pelo colorido e 
relações tonais que utiliza, essa paleta utilizada pelo artista foi construída paralelamente com o constante aperfeiçoamento de sua técnica, principalmente quando permanece na Europa entre 1929 e 1936.

$\mathrm{Na}$ tela, o descolar da face do plano de fundo e de seu próprio corpo faz com que o deslocamento de suas feições se encontre perpendicularmente na pureza de uma infância que está para além de felicidade de brincadeiras e hábitos infantis. Essa melancolia presente na obra foi uma temática presente nos grupos que participou. "Generación del '13" e "Montparnasse", foram responsáveis pelo anti-academicismo e anti-naturalismo que o artista passa a pontuar em suas telas em temáticas melancólicas, de intrigas, amor e morte. Esses grupos foram fundamentais para o desenvolvimento do pós-impressionismo presente em suas obras.

Esta infância a qual se retorna, não em caráter de representar uma criança chilena melancólica, nem a infância do artista que a retrata, mas sim, certa sensação sobre esta idade infantil, familiar e distante, perdida e por vezes lembrada, está, portanto, para além de possuir uma fruta em sua mão. $\mathrm{O}$ menino se interioriza em seu eu, levando o espectador a este mesmo lugar, num clima quente úmido de sentimentos tediosos que se misturam com a l'acedia: a ausência de vontade. Este sentimento que se aproxima ao enlutado, mas não se equivale. Longe de um não saber para aonde ir, mas um não querer andar até ali nem conhecer os cantos mais distantes de um armário de uma despensa cheia de guloseimas. É sim, um não querer partir, é gozar de uma amargura interior, é sentir até as raízes de todo campo sensorial humano a dor da perda, o tédio de uma vida não vivida num estupor. Neste estado letárgico de uma bílis negra, conceito atribuído na Idade Média e que mais tarde derivou-se para melancolia, patologicamente estava ligado ao baço e ao sangue grosso e seco que fluía deste órgão quando um ser que amava a aflição expelia no momento antecedente a sua morte uma bílis negra, um negrume. É nesta melancolia que se pode observar o deslocamento desta infância retratada, uma infância que normalmente não olhamos, mas que um dia sentimos e ao qual podemos retornar através dos olhos destas crianças, num sentimento de voltar para si mesmo como reconhecimento de algo que ficou retido em si próprio sobre um não pertencimento ao corpo cuja posse lhe escapa.

O cineasta iraquiano Abas Kiarostani (1940 -), em 1987, produziu o filme "Onde é a casa do meu melhor amigo?", onde Ahmad é um jovem garoto que estuda numa escola para meninos cujo regime rígido do professor desvela-se na obrigatoriedade de fazer a lição no caderno e não no livro ou em qualquer outro lugar. Seu amigo é ameaçado pelo mestre de ser expulso do colégio caso não faça as tarefas no lugar apropriado, já que era a terceira vez que o 
professor solicitava isto a ele. Retornando da aula Ahmad se depara com o caderno do seu amigo, o qual trouxe para casa por engano. Espantado e amedrontado com a possibilidade de seu amigo ser expulso, o menino solicita a mãe para poder ir devolvê-lo ao seu amigo. Esta, desgostosa, nega e diz para o filho ir fazer a sua lição e brincar. O menino contra a vontade da mãe sai em busca da casa do seu amigo, ao qual a única referência que obtém é que fica na vila vizinha. Passado o dia todo procurando, já tarde da noite ele acaba voltando pra casa e então resolve fazer a lição para o seu amigo. Kiarostani reproduz o infortúnio de uma busca incansável, um correr atrás do que não é alcançado na constante busca tediosa e ansiosa de Ahman e é nas crianças que o cineasta vê uma resposta à difícil política do país. Vítimas do autoritarismo de uma sociedade repressora ele observa o otimismo e certa sagacidade na busca por uma almejada justiça, ou amenização de sua difícil situação social no Irã.

Nas feições contorcidas e amarguradas da personagem ultrapassadas pelos tons terrosos do clima úmido do filme podemos também nos remeter a figura de "El chino", pintura do artista colombiano Fídolo Alfonso González (1883 - 1941). A infância deste artista esteve marcada pela morte de seu pai e pela luta que sua mãe enfrenta pela sobrevivência da família. É impossível ignorar a tristeza e as marcas profundas que esse trauma representou na vida do pintor. "El chino" é uma das obras que salienta a dor da perda, não sendo uma auto-representação de si em sua infância, mas está atrelado a um retorno ao mundo infantil pelo artista demarcado por traços dolorosos.

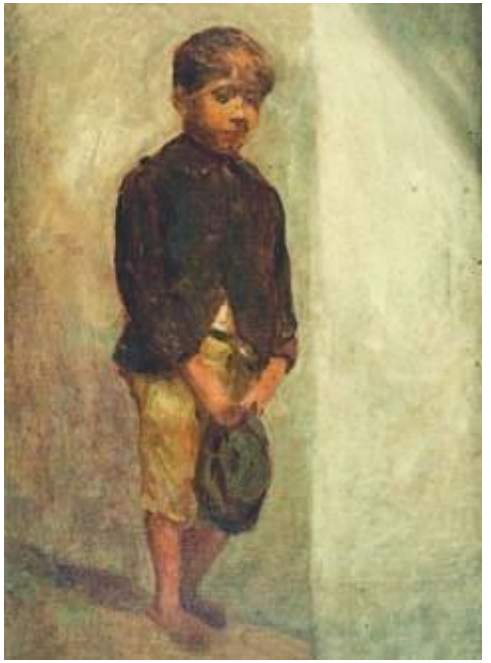

Figura 2

Tanto a personagem do filme, como o garoto retratado na pintura se unem numa alienação com o próprio corpo. Numa drenagem onde se projetam para um mundo exterior, num amortecimento de seus próprios afetos, num recair-se sobre si mesmo, virando-se do avesso em esquecimento. Na pintura de González, um menino caminha vagarosamente sem destino segurando seu chapéu, da mesma forma no filme de Kiarostani o garoto caminhava com rumo incerto imerso em si, neste mundo exterior, que é o mesmo espaço aonde o enlutado mergulha em meditação, entretanto uma diferença pontua-se: a melancolia dos enlutados difere-se da melancolia observada nas telas.

Walter Benjamin (1892 - 1940) afirma que "O luto é um estado de espírito em que o sentimento reanima o mundo vazio sob a forma de uma máscara, para obter da visão desse mundo uma satisfação enigmática" ${ }^{1}$. É um sentimento que se debruça sobre esse mundo

${ }^{1}$ BENJAMIN, Walter. Origem do Drama Barroco Alemão. São Paulo: Brasiliense, 1984. P. 162. 
melancólico, vazio, interiorizado, paralelo de alguém que não está mais ali. O enlutado passou pelo trauma da perda e todo o processo que se desencadeia após esta perda manifesta-se sintomaticamente através da melancolia. De forma contrária, as crianças apresentadas, em sua maioria, manifestam uma melancolia desprovida de tal trauma, de tal perda irremediável. O cerne do luto não está atrelado a qualquer afetividade do artista, nem a do expectador, mas a um sentimento que se dissocia desse sujeito que é o retratado, por algo interno a ele que é o objeto, ou seja, o que ou quem ele perdeu. E nesse esvaziamento do sujeito, nesta projeção para um mundo exterior que ambos, crianças e enlutados se unem, aproximando-se nesse mundo vazio, exterior, fora do próprio ser. É na mesma medida em que se exterioriza do ser ele se introjeta e penetra dentro deste ser, pois este mundo exterior está dentro do próprio ser humano, portanto interiorizado.

Em outras palavras, se considerarmos as sensações guardadas na obra de arte como algo familiar a Perséfone em sua temporada junto a Deméter, então será possível compreender que coube a Isaías Cabezón e a Fídolo Gonzalez problematizar nestas duas pinturas aqui tratadas a infância não como retrato, mas como cena onde o artista estranha seu próprio corpo, desterritorializando-se de si, vendo-se não como senhor de seu destino, mas como estrangeiro dês-possuído de si. Assim, embora Gonzalez tenha marcas desde sua infância de uma perda irremediável, ele não a retrata nesta tela, mas sim, estabelece um jogo onde este artista enlutado volta-se para si mesmo e para o cerne que é a própria perda manifestada na melancolia que se une à tela de Cabezón, ambos assim, se projetam para si e unem-se no vazio do esquecimento de si próprios.

\section{Quando o mundo se faz gélido e chuvoso}

Agora tentemos imaginar o ambiente gélido do submundo das trevas ao qual Perséfone esteve presa. Neste clima rigoroso a frieza e tristeza que a jovem teve que enfrentar se aproxima da melancolia como uma doença da alma, onde ela não via, nem ouvia o mundo ao seu redor. $O$ sentimento solitário que esteve presente durante todo o tempo em que permaneceu presa, resultando num próprio esquecimento de si. Envolta por tons terrosos e sobre chão batido, a menina da tela "La Urpila" fica presa em si da mesma forma que Perséfone, numa doença da alma. A obra pintada pelo artista pioneiro da pintura moderna na Argentina, Ramón Cornet Gomez (1868 - 1964), demonstra o isolamento para com o mundo e é responsável pela escolha de como estará daqui a um segundo. 


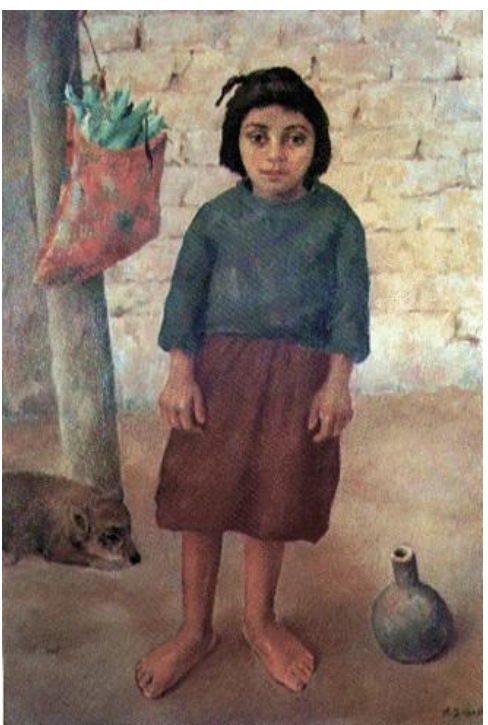

Figura 3

Este mesmo esquecer é também apontado por Luigi Pirandello (1867 - 1936), literato italiano no livro "Um, nenhum e cem mil" através do personagem Moscarda. Defendendo que a solidão nunca está presente conosco, mas ela só é possível na presença de um outro alguém, num estar só sem si mesmo e num não poder-se ver vivendo, este personagem reflete um não se ver em si, mas sim, ser visto por si, deste modo também Perséfone se vê de fora quando presa num mundo gélido e chuvoso junto a Hades, não olha para si através de um espelho, pois assim como Moscarda, ambos acreditam que há um abismo entre eles e todos os seres ao seu redor, já que ele nunca são o mesma pessoa para esta ou para aquela pessoa. Tanto a menina apresentada na tela, como Moscarda nunca eram o que eram pra si próprios e assim somos nós que definimos o nosso perfil de amanhã. "Há um minuto atrás você era outro não só um, mas cem outros, cem mil outros. Hoje vocês se fixam de um modo e amanhã de outro" ${ }^{2}$. Neste jogo de decisões esta jovem menina que pode ser vista como uma só, nenhuma e cem mil.

Nesta equivalência, assim como Ramón Gomes volta a sua infância para pintar a tela, Benjamin no texto "A infância em Berlim" escreve um conto intitulado "A despensa" onde através de uma estreita fresta do armário da despensa, uma mão penetra silenciosamente e começa a apalpar as delícias ali presentes, desde frutas cristalizadas, até amêndoas e passas, entrevistando-as uma a uma sentindo o gosto na boca de tudo o que tocavam, assim também em outro conto "Armários" ele revela a sensação de apalpar até os cantos mais recônditos de uma gaveta até encontrar, meias e outras peças macias para sentir o calor da lã.

Gozando destes sentidos tácteis e olfativos das crianças a que Benjamin se refere acaba levando a um mundo de imaginação e de conforto, de forma semelhante Gomes o faz sobre a tela, retornando aos sentidos infantis apurados ele procura explorar através das pinceladas sobre a tela, deparamo-nos para além de qualquer semelhança biográfica, mas sim, nos aproxima desse desvio rebatido sobre as crianças com nossa melancolia. A tela está para além de uma representação melancólica ou biográfica, estando, portanto, no abismo do encontro entre todas as personagens das obras aqui citadas, bem como dos artistas e dos espectadores, num jogo de equivalência onde todos são um, nenhum e cem mil.

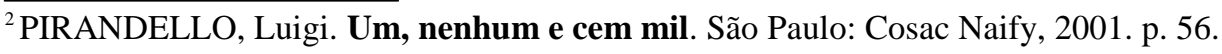


Este estar sem corpo que é problematizado na tela de Gomes é também a sensação que da mesma maneira aflige e perturba o filósofo Sartre (1905 - 1980), que no livro "A náusea" pontua o salivar como um voltar a si, "ela desliza por minha garganta, me acaricia - e eis que renasce em minha boca, tenho perpetuamente na boca uma pequena poça de água esbranquiçada - discreta - que roça minha língua" ${ }^{3}$. Com esta sensação acaba afirmando que a língua, garganta e saliva é ele próprio. Através do salivar que o autor sente-se volta a si e sai do esquecimento, da náusea, da sensação de não possuir sangue, estar sem corpo, a qual lhe afligia e lhe perturbava. Esta sensação de relembrar que é um ser humano que vive, porém, se dá ao contato com a tela citada, pois imergindo nos olhos dessa criança, sobretudo dos olhos que se perdem como algo mole, seco, bem como escamas de peixe, entramos em sua angústia, sua solidão e ao nos depararmos com a imagem como um todo feito de tecido, tinta, volume, luz e sombra nos projetamos a um desvio, na qual saímos desse abismo entre representação e representado.

Nessa curva, Pirandello descreve uma análise da imagem de Moscarda contra o espelho na tentativa de que seus olhos não tocassem seu reflexo: "Eu me sentia aqueles olhos. Via-os na minha frente, mas os sentia também aqui, em mim, sentia-os meus - aqueles olhos que já não estavam fixados em mim, mas em si mesmos. E, se quase não conseguia mais senti-los em mim, não mais os via". ${ }^{4} \mathrm{O}$ personagem desvela o esquecimento de si e o modo com que via seu olho nele mesmo, porém com o decorrer do tempo passou a não sentir mais seus olhos em si e nessa passagem de voltar a sentir seu corpo, quando nós, ao olharmos " $L a$ urpila" incansavelmente, nos fixamos em sua melancolia, nesta doença da alma que Gomes explorou em si mesmo, nos prendemos então a ela, e, entretanto, com o decorrer do tempo deparamos-nos em sua tinta, cor, volume e sombra: sendo, portanto uma tela.

Esta passagem do interior para o exterior da tela, rebate com a volta de Perséfone para junto de Demeter e seu sofrimento e angústia então cessam, numa melancolia que acaba se diluindo, num processo de imersão e consecutiva emersão deste sentimento presente na tela e em nosso próprio corpo.

\section{Quando o mundo se faz morno, insonso e seco.}

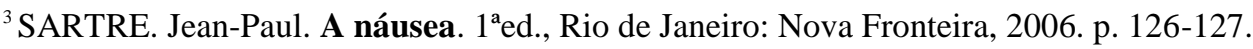

${ }^{4}$ PIRANDELLO, Luigi. Um, nenhum e cem mil. São Paulo: Cosac Naify, 2001. p. 36.
} 
Com o retorno de Perséfone à terra para junto de sua mãe, o mundo volta ao estado de florescência e fertilidade. Num jardim de clima ameno e morno onde os sujeitos voltaram a viver em harmonia nesta idade primaveril, neste mesmo acalanto do quintal de sua casa encontra-se "Nina Campesina", menina pintada pelo colombiano Fídolo Alfonso Gonzáles (1883 - 1941) onde ela permanece reservada da presença de pessoas e imerge em suas próprias brincadeiras solitárias.

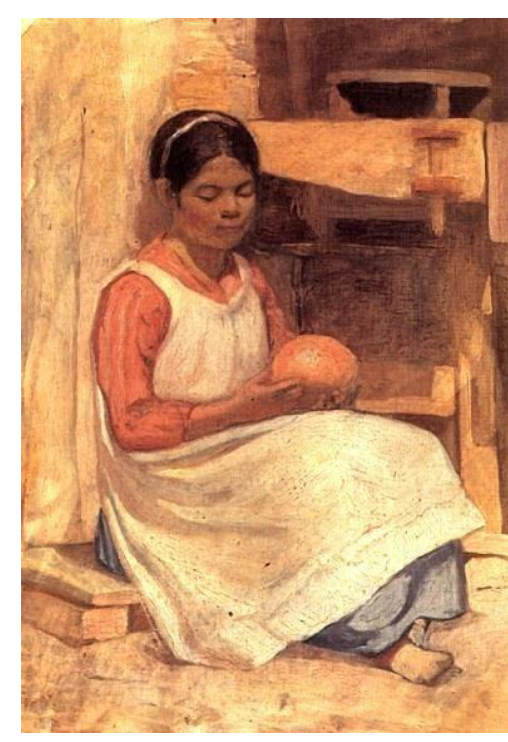

Figura 4

Semelhante solidão infantil foi discutida por Freud (1856 - 1939) no texto “Além do princípio do prazer" onde ele aponta uma criança de dezoito meses que sozinha num canto da sala, também longe de sua mãe e da proximidade de qualquer pessoa, ela penetrava nos objetos que estavam ao seu redor da mesma forma que Gonzáles apresenta a criança na pintura observada. Sempre agarrando estes objetos e os atirando para longe, dentre estes brinquedos havia um carretel de madeira com linha preso a ele. Da mesma forma o agarrava e o atirava para longe, simultaneamente resmungava expressões a qual sua mãe equiparou com a palavra "fort" de origem alemã que representava o "ir embora", já que o

carretel fugia de seu campo de visão e quando o puxava para seu encontro, no momento em que o via, saudava-o com um “ $d a$ ", ou seja: "ali”. Esses brinquedos fazem com que o desejo desses indivíduos se pontue. É no lançar para longe que tudo se contrai em desaparecimento, em sístole e em seu reaparecimento e repouso, a diástole, ocorre o retorno. É na verbalização deste desaparecer e re-aparecer que ocorre a simbolização deste jogo de "fort-da".

Entre o "fort", o lançar do objeto e perdê-lo de seu campo de vista e o "da", reencontro com este objeto, é que se encontra a pintura de Gonzáles. Neste entre, neste quase, no fio que se desenrola de maneira sutil sendo o elo de um movimento num ritmo anadiômeno de um ir e vir, no fluir e refluir deste objeto presente com esta criança que se interioriza em si mesma é que se encontra também "Sarita", menina apresentada na tela de Raul Soldi (1905-1994) aonde os traçados marcantes não impedem que as oposições cromáticas deixem de dialogar com o conjunto de toda a tela. Nas telas, ambas as meninas olham para um nada, para um lugar além e independente da sua presença, e nesse mergulho está presente o que as duas seguram com as mãos: bola e arco. Estas são então esse quase, esse objeto que produz este ritmo anadiômeno e nesta perda, no momento que o carretel desaparece do campo de visão da criança, algo resta: uma ausência, uma perda interior destas crianças, que é semelhante a uma 
construção abandonada, onde nesta ruína só restam, portanto, lembranças ao qual mergulhamos nas imagens que escapam como fogos de artifício. Poderíamos falar do assassinato da coisa, quando brinca a criança esquece da mãe, mata-a, da mesma forma o artista quando cria simboliza a coisa assassinada, ou seja, presentifica a distância pela criação de outra coisa, então não se trata de re-apresentação da coisa ausente, mas de criação a partir uma falta, eis uma certa familiaridade entre o gesto artístico e o gesto infantil e que ajudam a pensar que aqueles retratos não são uma mera reapresentação pictórica ou biográfica de um corpo de criança, mas a maneira pela qual cada artista incide as sensibilidades e percepções de sua própria condição.

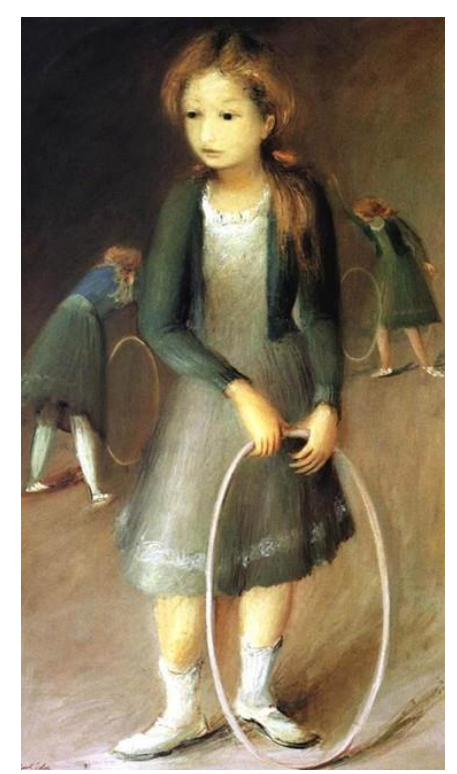

Figura 5

Nesta imersão melancólica para com os objetos, as telas problematizam para além de um desvelar de uma simples perda, mas a destrincham para com algo ou também de tudo, inclusive de nós mesmos. Assim como somos olhados pelo trauma destas crianças e estamos ameaçados a perder tudo, o personagem Werther do escritor Goethe, também vive neste limiar encontrando-se imerso na sua solidão causada por um amor não correspondido, fato este que o leva a cometer suicídio e o tédio que pairava a vida deste personagem refletia-se nas cartas que escrevia com estupor.

Neste limítrofe de estar fora de si que as telas evidenciam, acabou-se refletindo na solidão que Goethe descreve com

romantismo. Gozando muitas vezes desta sua vida paralela estando num certo limite entre sanidade e loucura, podemos equipar este sentimento com a náusea da qual nos apresenta Sartre numa ruminação dolorosa que alimentava. Afirmando que não conseguia parar de pensar reivindicando uma perturbação contínua, pois "se pelo menos pudesse parar de pensar, já seria melhor. Os pensamentos são o que há de mais insípido. Mais insípido ainda do que a carne. Prolongam-se interminavelmente e deixam um gosto esquisito. Será que isso não termina nunca?". 5 Assim, num esquecimento de si mesmo é que se encontram "Sarita", uma jovem menina que em contraposição com as outras crianças que se encontram no plano de fundo, ela pára de brincar, e assim estática em meio aos verdes pontuais e sutis da tela, ela se aproxima do personagem Werther, e da infortúnia náusea de Sartre. "Sarita" está no ritmo anadiômeno do fluir e refluir, prestes a lançar a qualquer momento seu arco para um além na qual a gravidade se assemelhará ao fio do carretel da criança descrita por Freud. No

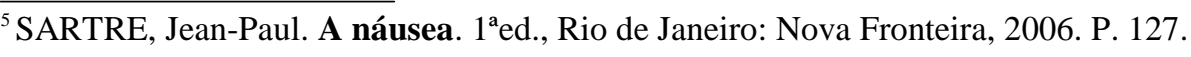


esquecimento de si mesmo é que Soldi se retém e se desenvolve numa operação até a um anacronismo e assim:

Torna a operação mesma de um desejo, isto é, um repor em jogo perpétuo, como o Fort-Da podia oferecer a repetição rítmica de um "ponto zero do desejo", e podia de certo modo fixar o infixável: ou seja, um laço de abandono que se torna jogo, que se torna uma alegria de ébano - que se torna obra. (DIDI-HUBERMAN, 1998, p. 115).

A melancolia e todo o sentimento responsável pela introjeção dentro de seus próprios pensamentos, este abandono de si mesmo pode então se assemelhar ao momento da própria criação artística. E assim, na solidão de uma experiência exterior, no gozo de desfrutar desta doença da alma que o artista cria para além de uma representação. As imagens pictóricas aqui apresentadas parecem situar-se para além da representação da infância embora reivindiquem este momento tão sutil onde se projetam para além de seu corpo provocando um abismo entre o mundo terreno, morno, insosso e seco em que vivem os mortais e o mundo da criação, o qual de tão particular e próximo a si mesmo está tão distante e fora de si, exterior ao próprio corpo do pintor. Talvez porque a distância da criança para o mundo dos adultos seja parecida com a do artista para o mundo dos simples mortais?

\section{REFERÊNCIAS BIBLIOGRÁFICAS}

1 BENJAMIN, Walter. Origem do Drama Barroco Alemão. São Paulo: Brasiliense, 1984. 
2 BENJAMIN, Walter; BARBOSA, Jose Carlos Martins. Rua de mão única. 5. ed. São Paulo: Brasiliense, 1995.

3 BULFINCH, Thomas. O livro de ouro da Mitologia - História de deuses e Heróis. 9 ed. Rio de Janeiro: Ediouro, 2000.

4 DIDI-HUBERMAN, Georges. O que vemos, o que nos olha. São Paulo: Ed. 34, 1998. FREUD, Sigmund. Além do princípio do prazer. ESB., vol. XVIII. Rio de Janeiro: Imago, 1946.

5 GOETHE, Johann Wolfgang Von. Werther. 2.ed. São Paulo: Abril Cultural, 1971.

6 PIRANDELLO, Luigi. Um, nenhum e cem mil. São Paulo: Cosac Naify, 2001.

7 PRIGENT, Hélène. Melancolie - Lês métamorphoses de la dépression. Paris : Gallimard, 2005 .

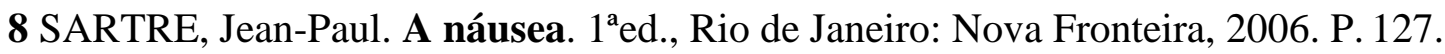

\section{REFERÊNCIA DAS IMAGENS}

1 Isaías Cabezón Acevedo. Nino de la naranja, s/ data. Óleo s/ tela. Museu Nacional de Bellas Artes do Chile. Disponível em:

<http://www.artistasplasticoschilenos.cl/artistas.nsf/560c3d14905ab7eb04256bfa006b70a1/31 aacd45191de9a2042569a90056f672?> Acesso em 21/03/2008.

2 Fídolo Alfonso González. El Chino, s/ data. Óleo s/ tela, 35x25 cm. Disponível em: <http://www.colarte.arts.co/colarte/conspintores.asp?idartista=490> Acesso em 24/04/2008. 3 Ramon Cornet Gomez. 'La Urpila', 1946. Óleo s/ tela, 130 x 89 cm. Colección Museo Nacional de Bellas Artes, Buenos Aires. Disponível em:

<http://www.fundacionkonex.org/ingles/bienales_del_arte/cornet_ramon_gomez.asp> Acesso em 17/05/2008.

4 Fídolo Alfonso González. Nina Campesina, 1917. Óleo sobre cartão, 23 x $17.5 \mathrm{~cm}$.

Disponível em: < http://www.museonacional.gov.co/body_nina_campesina.html> Acesso em 24/04/2008.

5 Raul Soldi. Sarita, 1947. Óleo s/ tela, 70 x 123 cm. Disponível em: <http://www.allsa.com/ArtistaRaulSoldi.htm> Acesso em: 2/02/2008. 